\title{
A PRODUÇÃO DE SENTIDO DA EXPERIÊNCIA DE MARCA COM BASE EM ESTRATÉGIAS ORGANIZACIONAIS DA LÓGICA DOMINANTE DE SERVIÇOS: EXPERIÊNCIAS DA MARCA HEINEKEN.
}

\author{
Production of the meaning of the brand experience, based on the \\ organizational strategy fo the logic dominant in the services: experience of the \\ heineken brand. \\ La producción de sentido de experiencia de marca basado en estrategia \\ organizacional en lógica dominante en servicios : experience heineken la \\ marca.
}

Bruna Schuck Nunes
Mestranda em Indústria Criativa na Universidade Feevale
bsnunes@hotmail.com
Mary Sandra Guerra Ashton
marysga@feevale.br
Dusan Schreiber
Pesquisadora e Docente na Univeridade Fevale
Pesquisador e Docente na Universide Fevale
dusale.br
Serje Schmidt
Pesquisador e Docente na Universidade Feevale
serje@feevale.br

\section{Resumo}

O presente estudo tem o objetivo de identificar como a produção de sentido da Experiência de Marca com base na Lógica Dominante de Serviços pode contribuir nas estratégias organizacionais de gestão de marca. O método de pesquisa escolhido para este estudo é pesquisa exploratória descritiva, qualitativa, estudo de caso e análise semiótica. Para elucidar o objetivo proposto, este estudo terá como premissa um estudo de caso da marca Heineken, a qual destaca-se pela utilização de estratégias organizacionais com características criativas realizadas pelas experiências da marca. Como resultado, espera-se compreender a relação dos consumidores com a marca Heineken, que a partir das experiências compartilhadas entre marca e consumidor, promova a produção de sentido subjacente à experiência do consumidor com a marca.

Palavras-chave: Experiência de marca. Produção de sentido. Lógica Dominante de Serviços. 


\begin{abstract}
This study aims to identify how the production of the meaning of Brand Experience, based on the Logic Dominant in Service can contribute to the organizational strategies of the brand management. The research method chosen for this study is descriptive exploratory research, qualitative, case study and semiotic analysis. To elucidate the proposed objective, was performed a case study of the Heineken brand, which is considered a expert in developing organizational strategies with creative features that carry out the experiences of the brand. As a result, it is expected to understand the relationship of consumers with the Heineken brand, which stem from the experiences shared between brand and consumer, as promotes the production of underlying meaning to the consumer experience with this specific brand.
\end{abstract}

Keywords: Brand experience. Production of meaning. Dominant Logic in Service.

\title{
Resumen
}

Este estudio tiene como objetivo identificar cómo la producción de sentido de la experiencia de marca basado en Servicio dominante lógica puede contribuir en las estrategias de organización de una marca. El método de investigación elegido para este estudio es la investigación descriptiva exploratoria, cualitativa, caso testudo y análisis semiótico. Para dilucidar el objetivo propuesto, este estudio hará premisa de un estudio de caso de la marca Heineken, que se destaca por el uso de estrategias de organización con características creativas llevadas a cabo por las experiencias de la marca. Como resultado, se espera que entender la relación de los consumidores con la marca Heineken, que a partir de las experiencias compartidas entre la marca y el consumidor, promueve la producción de significado que subyace a la experiencia del consumidor con la marca.

Palabras-clave: Experiencia de marca. La producción de significado. Lógica dominante in Servicio.

\section{INTRODUÇÃO}

Diversas estratégias podem ser utilizadas pelas marcas, uma vez que o foco não pode mais ser dado apenas para a venda final. Tudo se torna uma construção e cada etapa pode ser decisória na percepção dos públicos, os quais podem ser diversos e gerar repercussões diversas. Nessa perspectiva, uma, entre diversas, estratégias utilizadas pelas marcas é a Experiência de Marca, que também é identificada como marketing de experiência, marketing experimental, brand experience, entre outros.

As estratégias de Experiência de Marca despertam diferentes emoções e sentidos naqueles que participam deste momento de troca entre o consumidor e marca. As ações desenvolvidas pelas marcas, se bem elaboradas e aplicadas, afloram sensações singulares, às quais serão remetidas ao imaginário dos públicos ao imaginar determinada 
marca. Desta forma, as marcas que adotam estratégias organizacionais que buscam ser criativas e relacionadas à experiência, possibilitam o contato direto com diferentes públicos, e relacionam vínculos entre a marca e aqueles que participam ou conhecem as experiências criadas. Com isso, tais ações tornam-se diferenciais positivos para as marcas. Landry (2013, p. 82) afirma que "o desejo de gerar ricas experiências faz de um modelo um pré-requisito para o sucesso".

Para que as experiências geradas pelas marcas obtenham um resultado desejado ou ainda possam superar as expectativas geradas, o branding torna-se, então, um fator estratégico. O "branding é o conjunto de ações ligadas à administração das marcas. São ações que, tomadas com conhecimento e competência, levam as marcas além da sua natureza econômica, passando a fazer parte da cultura, e influenciar a vida das pessoas" (MARTINS, 2006, p.9). Isto posto, esta gestão das marcas possibilita uma compreensão mais aflorada das estratégias utilizadas, bem como fortalece as escolhas feitas para cada momento e público.

Atrelado a isso, está o poder de decisão de compra, a qual é definida por diferentes causas e motivações. A emoção é ilimitada e relacionada a novas ideias, inspirações e experiências. As sensações que compõe a decisão do consumo e da percepção formada de uma marca são diversas e tendem a estar relacionadas ao emocional, "poucos consumidores tomam decisões de compra baseados unicamente em critérios racionais" (JENKINS, 2008, p. 108).

A Experiência de Marca tende a criar novas estratégias a partir de novas ideias, uma vez que Schmitt (2001) salienta diferenças em cada conceito: o marketing tradicional utiliza ferramentas analíticas e quantitativas e o experimental utiliza métodos diversos: a proposta é adequar a metodologia às situações - empregando boas ideias. Sendo assim, o consumo é instigado a partir de ações diferenciadas realizadas pelas marcas, buscando ser diferente e atraindo o consumo. "Os consumidores querem ser estimulados, divertidos, instruídos e desafiados. Eles procuram marcas que lhe possam fornecer experiências e depois passem a fazer parte da sua vida" (SCHIMITT, 2001, p.47).

Corroborando a isso, o marketing e o branding passam em uma velocidade intensa por transformações conceituais, uma vez que a percepção e o comportamento dos consumidores muda constantemente. Visto isso, uma forma de reavaliar as estratégias organizacionais utilizadas pelas marcas, justifica-se perceber as definições da Lógica Dominante de Serviço (LDS), a qual traz à tona a discussão sobre as expectativas e aquilo que os consumidores buscam. Não apenas o consumo de produtos, os consumidores buscam uma relação maior 
com a marca, o consumo dos serviços de forma geral, criando um valor para toda a proporção da marca, tudo aquilo que ela pode ofertar, além do produto final (VARGO; LUSH, 2004).

Sob esta ótica, o tema proposto se faz relevante uma vez que a experiência possui retornos positivos às marcas e possui uma repercussão relevante frente aos consumidores, muitas vezes sendo percebidas pelos conceitos da Lógica Dominante de Serviço, com um envolvimento da marca como uma ofertante de serviços, além do produto final. Essa estratégia sendo criativa, bem planejada e aplicada passa a ter maior relevância, uma vez que a percepção dos públicos para a ser de maior qualidade e a repercussão gerada se torna positiva. Isto posto, os consumidores passam a ter uma ótica diferenciada a partir de tais estratégias, podendo se tornar fiel a marca frente a esta troca de experiências.

Nesta perspectiva, a Experiência de Marca, a partir de estratégias criativas, podem gerar diversos sentidos e sensações em seus distintos públicos. Para cada indivíduo o sentimento é singular, assim como as experiências e situações em que vive junto à marca. Por meio disto, cada um passará a ter uma relação única com a marca, possibilitando que o envolvimento seja cada vez maior. Isso se justifica com o estudo de caso da marca Heineken, que não apenas visa o consumo do seu produto final, a cerveja, mas visa criar experiências entre a marca, produtos e seus diversos públicos. Assim, o consumidor não adquire apenas um produto, neste caso elucidado pela cerveja, mas sim, consome a marca, fixa a marca e repercute a marca, beneficiando-se com os serviços por ela oferecidos, em diferentes instâncias.

Visto isso, o presente estudo tem como objetivo identificar como a produção de sentido da Experiência de Marca com base na Lógica Dominante de serviços pode contribuir nas estratégias organizacionais de uma marca. Para o desenvolvimento desse estudo se propôs uma análise teórica reflexiva, norteada pelo aprofundamento conceitual das Experiências de Marca para a compreensão das dinâmicas diárias inscritas nos fazeres e saberes cotidianos que envolvem este tema e os sentidos produzidos por elas, além de compreender a Lógica Dominante de Serviço a fim de compreender a relação entre marca e seus públicos, utilizando o método exploratório descritivo, pesquisa qualitativa a partir de um estudo de caso, nesta pesquisa com a marca Heineken.

Acredita-se que esse estudo se justifica por ser uma contribuição social, a qual o impacto se faz relevante e desafiador, à medida que criar novas estratégias e definições norteia e estimula o novo a partir da criatividade. Esta pesquisa se propõe a instigar, a partir 
da contribuição de autores em destaque referente ao tema, a relação dos autores e contextos com o desenvolvimento dos assuntos propostos.

\section{GESTÃO DAS MARCAS: OS PÚBLICOS E OS VÍNCULOS EMOCIONAIS}

As marcas passam por mudanças constantemente, se pensar em um comparativo de comportamento empresarial e organizacional do século XXI. Se antes o foco principal era venda e o destaque entre concorrentes a partir de quantidade, atualmente o foco se dá na qualidade, envolvimento, relação e experiências entre as marcas e seus diversos públicos. A transição da Sociedade Industrial para a Sociedade do Conhecimento trouxe novos conceitos e interpretações para marcas, consumidores e para a sociedade como um todo. Conceitos abordados em uma era pós-industrial, a qual o foco se dava no crescimento e desenvolvimento local, bem como no crescimento industrial, passam a ser repensados em virtude de uma nova era, novos pensamentos e investimentos.

O conhecimento é o grande diferencial para os indivíduos e para o crescimento econômico, uma vez que a partir dele que se pode repensar e criar novas estratégias, diferenciando, assim, as marcas. "Na sociedade do conhecimento a realidade é bem diferente. O conhecimento passa a ser o novo motor da economia e se transforma no principal fator de produção" (CAVALCANTI, 2001, p. 24).

A preocupação com a imagem e a percepção dos indivíduos, da sociedade, do governo, dos consumidores e até mesmo dos concorrentes, é um imenso desafio para a gestão de uma marca. A partir dessas opiniões e das repercussões geradas destes públicos, se constrói e se desenvolve uma marca. $\mathrm{O}$ que se fala sobre ela pode ser interpretado de distintas formas, uma vez que a relação entre quem repercute algo é única com esta marca. Para isso, conhecer os públicos é fundamental. De acordo com Ferrão (1997), quanto a estes públicos "Identificá-lo é o primeiro desafio. Estabelecer contato, o segundo desafio. Mantê-lo, o terceiro. E ampliá-lo, o último" (FERRÃO, 1997, p. 124).

Tanto na criação quanto no desenvolvimento e atualizações das marcas, criam-se posicionamentos e identidades a partir das escolhas de fatores como valores, objetivos, serviços e produtos, estrutura física e de pessoal, entre outras. A marca passa a ser o resultado destas múltiplas escolhas, um final que pode contribuir para o posicionamento estratégico. Final este que se torna subjetivo, tendo em vista que a marca passa por constantes mudanças, se torna uma construção diária que muda conforme as variáveis internas (da própria marca) e 
externas (do mundo, do cenário que faz parte, das evoluções humanas e tecnológicas) (NIEMEYER, 2002).

Um termo em inglês muito utilizado atualmente é o branding, cujo significado, para Gracioso (2008, p.22), é “o de um processo de desenvolver e manter marcas, táticas e estrategicamente, com o objetivo de criar uma imagem única - e positiva - para um produto ou serviço". Além disso, o branding está relacionado a uma nova filosofia de gestão, como algo de grande valia. É a marca sendo vista como uma preciosidade que deve ter grande cuidado. . Sob esta ótica, o "branding é o conjunto de ações ligadas à administração das marcas. São ações que, tomadas com conhecimento e competência, levam as marcas além da sua natureza econômica, passando a fazer parte da cultura, e influenciar a vida das pessoas" (MARTINS, 2006, p.9).

Para Semprini (2006, p.41) "As marcas continuam a dar segurança, cumprindo sua função de referência, fator de identificação. Diante de uma hiperescolha desconcertante, o consumidor pode decidir se orientar graças à clareza do discurso ou à familiaridade de uma marca conhecida". Visto isso, o consumidor faz suas escolhas a partir de diversos contextos, de acordo com seus valores, gostos e identificações, e cabe às marcas utilizarem estratégias para manter-se presente e atrair os consumidores. "Nesse sentido, pode-se dizer que a multiplicação da oferta torna ainda mais necessária a presença das marcas" (SEMPRINI, 2006, p.41).

O branding passa a ser um aliado das marcas, visto que seu diferencial está na forma de ver o todo e não apenas áreas isoladas trabalhando sem comunicar-se entre si. Com isso, a percepção da marca passa a ser vista pela junção de cada ação e cada área e não apenas por fatores isolados. Kreutz $(2012$, p.1), afirma que "as marcas são formas simbólicas que interagem com seus públicos para conquistá-los".

As organizações contemporâneas passam por uma transformação mercadológica, por reestruturações e modificaram seus posicionamentos para atingir de forma mais qualificada seus públicos. Nesse sentindo, o branding veio com o conceito de agregar o posicionamento das organizações valorizando as identidades coorporativas e posicionando as marcas de forma positiva nas mídias. Para Ries (2000, p.4) "um bem sucedido programa de branding se baseia no conceito de singularidade", fazendo com que o cliente sinta e imagine que seu produto ou serviço é único no mercado, persuadindo de forma a convencer seus stakeholders a qualidade daquilo que representa uma marca. 
Para que esta gestão seja planejada e bem aplicada, faz-se imprescindível pensar em cada público, não apenas no consumidor final. Os públicos envolvidos ou os stakeholders "termo em inglês muito usado para identificar esses grupos" (DUAILIBI, 2009, p.59), são fundamentais para a assertividade de cada estratégia, pois cada um possui suas particularidades e um envolvimento diferente com a marca.

O consumidor de fato é o principal estímulo de uma marca, é para ele que se desenvolvem novos produtos, novos serviços, novas ideias, é vislumbrando o consumidor que se traz à tona uma motivação. "O termo consumidor indica aquele que compra o produto ou serviço para consumir ou usar" (DUAILIBI, 2009, p.59) e é visando a satisfação deste público que as estratégias são planejadas.

Cabe salientar que inúmeros outros públicos podem ser atingidos com as estratégias, como o público interno (funcionários), a comunidade, os formadores de opinião, e cada um possui a sua importância e relevância para a marca como um todo. Sobre os públicos de interesse pode-se identificar "pessoas ou outras empresas que têm algum interesse no resultado da organização, como investidores ou acionistas, fornecedores, revendedores, funcionários, mídia, sociedade em geral, incluindo, entre outros grupos de clientes e de consumidores" (DUAILIBI, 2009, p.59).

A imagem e a reputação de uma marca são imprescindíveis para seu sucesso, uma vez que uma imagem negativa pode provocar inúmeros resultados negativos à mesma, a partir do momento em que a percepção de uma pessoa pode ter uma repercussão considerável, a ponto de influenciar outros indivíduos. Da mesma forma, a repercussão positiva também pode ser intensa com a propagação de informações positivas pelos públicos. Quanto mais informações boas forem repassadas, maior a intensidade de um indivíduo estar ligado a uma marca e, assim, fazer parte da sua vida (FERRÃO, 1997).

A partir da construção das estratégias da marca, somado com as percepções dos públicos, as marcas devem ter uma preocupação com a sua imagem, uma vez que retornos positivos são identificados a partir das percepções dos públicos. A imagem da marca pode ser definida como a forma que seus públicos a percebem, a impressão que as pessoas possuem a seu respeito. Essa impressão pode ser percebida de forma positiva ou negativa, de acordo com as experiências obtidas com a marca (GRACIOSO, 2008).

O que faz um público escolher uma marca e não outra está diretamente relacionada às suas percepções e opiniões sobre ela. As diferenças positivas serão identificadas pelo público como fator de decisão. Gracioso $(2008$, p. 27$)$ ressalta que "a concorrência entre as marcas de 
uma mesma categoria se baseava em diferenças concretas de qualidade, muito mais do que em conotações subjetivas criadas pela propaganda". Atualmente, as relações com as marcas são inúmeras, não apenas voltada a sua qualidade, mas baseada por uma série de experiências e opiniões, voltadas à imagem obtida da marca. "Se a marca está na cabeça do consumidor, é por meio dela que cada novo movimento da empresa será analisado" (JUCÁ e TORTORELLI, 2008, p. 21).

A imagem é a forma que os públicos veem uma marca, podendo possuir diferentes imagens com seus diferentes públicos. Todavia, sua identidade corporativa não muda de acordo com seus públicos, ela consiste conforme suas estratégias e teorias adotadas (pessoal, serviços, crenças e valores). Já a Identidade Visual é a "manifestação visual de sua realidade, conforme transmitida por meio do nome, logomarca, lema, produtos, serviços..." (ARGENTI, 2006, p.80).

Por sua vez, a reputação de uma marca é de suma importância, podendo influenciar no resultado final, como retornos financeiros. Para Fascioni (2006, p.30) “A reputação é um juízo de valor que se efetua sobre a imagem". Nessa perspectiva, a confiança é fundamental para os públicos, relacionando-se com a marca por acreditar em seus benefícios e essência. Muitas vezes a confiança é construída por meio de uma situação ou experiência, por isso, cada momento com a marca pode ser decisivo. "Serviços são intangíveis e se compra na base da confiança. É isso que as marcas de hoje procuram transmitir" (GRACIOSO, 2008, p. 32).

"Os profissionais de marketing procuram moldar a reputação das marcas não através de uma transação individual, mas através da soma total das interações com o cliente" (JENKINS, 2008, p.98). E neste contexto, a proporção de experiências faz-se fundamental na relação com um indivíduo bem como na percepção de diferentes públicos frente à uma marca. As estratégias que em séculos anteriores focavam apenas na compra e lucratividade, mais focada no retorno financeiro imediato, mas sem se preocupar com uma relação duradoura, obteve mudanças. "Não querem apenas que o consumidor faça uma única compra, mas que estabeleça uma relação de longo prazo com a marca" (JENKINS, 2008, p.98).

Criar vínculos emocionais com os públicos faz de uma marca mais próxima dos seus públicos, a partir de um engajamento, uma preocupação é atrair o consumidor e estimular a produção de sentido naqueles que procuram a marca. A emoção pode ser percebida de distintas formas, ela é intensa e diversa, capaz de causar sensações únicas e percepções que fixam na lembrança. Visto isso, ao criar vínculos e gerar emoções nos públicos, as marcas tornam-se diferenciadas, fazendo com que este envolvimento seja decisório na escolha de uma 
marca para outra. Ferrão (1997, p. 22) salienta que "o que existe de mais natural em nós é a capacidade que temos de nos emocionar, de rir, de chorar, de amar".

A interação entre as marcas é provocada a partir das experiências geradas, por meio das situações vivenciadas, das sensações causadas, gerando então as percepções dos públicos, da imagem percebida. "É como se houvesse uma transmissão de emoções, e essa sincronia de estudo de espírito determinaria se sentimos que uma interação foi boa ou não. Interação é a troca de emoções” (FERRÃO, 1997, p. 39). Essa interação é primordial para as possíveis decisões de escolha.

Após a construção de vínculos e a criação de uma relação por meio de experiências e consumo, os consumidores tendem a aproximar-se das marcas, procurar interagir de forma mais intensa, conhecer melhor sobre a marca e o que se fala sobre ela, além de gerar informações referentes às marcas. Nessa perspectiva, os consumidores engajados à marca, que visam essas interações, podem vir a torna-se fãs da marca. Os diferenciais são estímulos para o interesse dos stakeholders, com ênfase nos consumidores, gerando relações fortalecidas e enfatizadas. "São esses diferenciais que nos lançam ao encontro fulminante desse consumidor, amanhã fidelíssimo" (FERRÃO, 1997, p. 125).

As marcas buscam cada vez mais compreender as motivações dos consumidores buscarem e escolherem uma marca, à medida que o emocional determina, muitas vezes, a compra. Uma relação criada desperta a emoção para criar laços e as marcas que despertam este interesse em seus públicos, cria um relacionamento de troca, no qual a marca proporciona emoções a partir de produtos, serviços, conteúdos e experiências.

\section{A EXPERIÊNCIA DE MARCA: ESTRATÉGIAS QUE GERAM EXPERIÊNCIA E EMOÇÃO}

Cada vez mais as marcas percebem a necessidade da criatividade para seu posicionamento. Isso se dá pelas inúmeras opções com que os consumidores se deparam em tempos atuais. Para que uma marca possa se destacar frente a seus concorrentes necessita ter diferenciais, compreender as reais necessidades de seus stakeholders e de que forma podem aproximar as relações entre marca e consumidor.

Frente ao desenvolvimento das ações de marcas em busca do diferencial e da criatividade, as estratégias vêm se adaptando ao gosto e à necessidade do consumidor à medida que os públicos se tornam mais exigentes e o acesso à informação evolui em uma 
velocidade impar. A informação que antes possuía uma trajetória e estava centralizada em poucos meios de comunicação, se expande com o desenvolvimento da internet e torna o acesso mais fácil, a quantidade de informação aumenta e, consequentemente, a dificuldade de atrair públicos a informações que favoreçam as marcas.

Quanto mais estratégias que compreendam seus públicos forem realizadas, mais esta marca estará relacionada às questões favoráveis com seus públicos. Para Levinson (2004, p.15) "a criatividade está levando as pessoas a mudar de ideia a ponto de passarem a querer comprar aquilo que sua empresa estiver vendendo". A partir de estratégias criativas torna-se mais comum a busca pelo consumo à marca.

Para que a criatividade possa ser fundamental em estratégias de branding, é necessário o conhecimento. Quanto mais conhecimento as pessoas possuírem sobre a marca, produtos, concorrentes, seus públicos de forma geral, maiores as chances de assertividade em suas estratégias. Tanto a criatividade, quanto o conhecimento são fundamentais para estratégias de brand experience ou ações de marketing. Para tais ações e estratégias que se utilizam mídias não convencionais é imprescindível a criatividade, visto que é precisa realizar ações diferentes, as quais estarão interligadas à marca bem como o conhecimento, visto que inúmeras análises são necessárias para a realização de uma ação de brand experience. “Quanto mais você souber, mais criativo poderá ser. Quanto mais você souber, mais inspirado poderá ser. Quanto mais você souber, maiores serão as possibilidades de sucesso dos propósitos verdadeiros da criatividade..." (LEVINSON, 2004, p. 16).

Ações não convencionais, como o brand experience, possuem inúmeras vantagens para um marca. Isso porque não se apresenta simplesmente um produto ou um serviço, mas se cria um envolvimento maior, uma relação mais intensa. Para Levinson (2004, p.19) as pessoas visam diferenciais, aquilo que as envolve e "essas pessoas não se impressionam com as palavras, imagem, música ou os efeitos especiais. E muito menos com a celebridade que possa estar endorssando o produto ou com uma fotografia genial. O que as impressiona é a ideia" (LEVINSON, 2004, p. 19).

Uma tendência que vem sendo estudada trata-se da economia da experiência a qual "se adapta à ideia de que o mundo está cada vez mais dominado pelos setores baseados na imaginação" (LANDRY, 2013, p.80). A imaginação e a criatividade são diferenciais para as marcas, uma vez que inúmeras delas buscam chamar a atenção dos consumidores por meio de estratégias atrativas. Visto isso, destacar-se é fator decisório em um meio em que estratégias convencionais passam a manter as marcas estagnadas. 
A busca pela criação e adaptação de novas estratégias para as Experiências de Marca impulsionam o sentimento desenvolvido por esta do âmbito emocional, o qual mantém vínculos entre algo muitas vezes desenvolvido por boas experiências. De encontro a isso, a criatividade se torna um diferencial para as marcas, frente aos diferentes públicos, sejam eles internos ou externos. Cada público passa a ter uma percepção da marca a partir das relações criadas, das experiências proporcionadas e daquilo que tem conhecimento sobre ela. Diante dessa realidade, "a criatividade não está apenas preocupada com o novo ou com uma fraqueza vaga. Ser criativo de modo eficaz significa ter o discernimento e saber quando ser flexível e aberto e quando ser mais concentrado e fechado ou obstinado e persistente" (Landry, 2013, p.38).

Diferentes marcas estão à disposição dos consumidores e a cada dia passam a utilizar estratégias cada vez mais atrativas para atrair mais consumo. Para isso, a criatividade se faz necessária para o destaque de uma marca entre os consumidores. Howkins (2013, p.13) afirma que a "criatividade é a capacidade de gerar algo novo. Significa a produção por parte de uma ou mais pessoas, de ideias e invenções que são pessoais, originais e significativas". Nessa perspectiva, as marcas devem planejar e utilizar de estratégias que atraiam os diversos públicos de forma positiva, e o fator emocional se torna decisório no poder de escolha de uma marca. "O processo criativo é uma técnica de resolver problemas, a qual pode ser aplicada a todas as atividades humanas e não apenas à atividade específica de criar boa comunicação" (DUAILIBI, 2009, p.10).

As estratégias de Experiência de Marca despertam diferentes emoções naqueles que participam deste momento de troca entre o consumidor e marca. As ações desenvolvidas pelas marcas, se bem elaboradas e aplicadas, afloram sensações singulares, às quais serão remetidas ao imaginário dos públicos ao mentalizar determinada marca. Desta forma, as estratégias que adotam a experiência, possibilitam o contato direto com diferentes públicos, e relacionam vínculos entre a marca e aqueles que participam ou conhecem as experiências criadas. Com isso, tais ações tornam-se diferenciais positivos para as marcas. Landry $(2013$, p. 82) afirma que "o desejo de gerar ricas experiências faz de um modelo um pré-requisito para o sucesso".

Atrelado a isso, está o poder de decisão de compra, a qual é definida por diferentes causas e motivações. As sensações que compõe a decisão do consumo e da percepção formada de uma marca são diversas e tendem a estar relacionadas ao emocional, "poucos consumidores tomam decisões de compra baseados unicamente em critérios racionais" (JENKINS, 2008, p. 108). As emoções podem ser geradas por meio de diferentes sentidos, 
tais como o tato, no qual as marcas despertam interesses através da sensação dos produtos e seus experimentos, por meio do olfato, despertando o imaginário por meio de cheiros que sejam relacionados à marca, ou ainda por meio dos vínculos emocionais, como estratégias que ocorrem em datas comemorativas, relacionadas à família, times, preferências dos indivíduos. Tudo isso, e também de outras formas, desperta a curiosidade e gera a experiência, gerando uma relação dos públicos e suas preferências.

Cada Experiência de Marca possui um planejamento, avaliado conforme os públicosalvo da marca, características dos consumidores, características da própria marca e marketing, isto é, em que mídias estas estratégias atingirão de forma eficiente e eficaz o público que deseja ser atingido. Para tal, o interesse está interligado à repercussão positiva a ser gerada com a experiência, quanto maior for o público atingido, maior a repercussão causada. Para isso, “a experiência não deve ser contida em uma única plataforma de mídia, mas deve estender-se ao maior número delas" (JENKINS, 2008, p. 106). Entretanto, de nada adianta a quantidade atingida se a estratégia não atingir o público específico que se deseja. Jenkins (2008, p.106) ainda salienta que "a extensão da marca baseia-se no interesse dos públicos em determinado conteúdo, para associá-lo repentinamente a uma marca".

Independente do produto, serviço ou conteúdo fornecido por uma marca, deve ser planejada para seus públicos e com o intuito de se destacar, independente do seu ramo de atuação no mercado. Por isso, as estratégias de Experiência de Marca permitem ao consumidor conhecer a marca, suas possibilidades e criar vínculos a partir de uma troca de relação. "Nesse universo de domínio das marcas, os produtos deixam de serem pacotes de características funcionais e passam a ser meios para fornecer e melhorar as experiências para o consumidor" (SCHMITT, 2001, p.26).

Cabe salientar que o consumo não é apenas efetivado pelo produto ou serviço em si, mas também pelo que ele gera e pelo que a marca proporciona. E isso acaba sendo uma tendência, visto que cada vez mais as marcas visam essa geração de experiência cada vez com maior intensidade. Hill (2003) observa essas tendências como uma crescente oferta de experiências entre as marcas e seus públicos. O consumidor já avalia seu consumo visando os benefícios deste consumo e avaliando que "a experiência é o próximo serviço" (HILL, 2003, p 229), criando expectativas por algo que possa ocorrer e envolve-lo.

Diferentemente do século passado, no qual os consumidores tinham acesso a poucas marcas para cada produto e que utilizavam apenas o que estavam acostumados a consumir, no século XXI, a partir da rapidez e facilidade do acesso à informação e tecnologia, o 
consumidor está diante de incontáveis marcas, com diferentes benefícios a oferecer, acentuando a necessidade da experiência positiva. Schmitt (2001, p.47) salienta que "os consumidores querem ser estimulados, divertidos, instruídos e desafiados. Eles procuram marcas que lhes possam fornecer experiências e depois passem a fazer parte da sua vida".

Algumas marcas se destacam a partir das estratégias que utilizam de Experiência de Marca. Não há um padrão para estas ações, uma vez que ser diferente e atrair os públicos a partir de algo não esperado, não convencional e que demonstre a preocupação em realizar algo positivo aos stakeholders é o que faz com uma marca tenha sucesso.

\section{LÓGICA DOMINANTE DE SERVIÇO E SUAS ESTRATÉGIAS ORGANIZACIONAIS}

Para que as organizações e marcas se destaquem perante as demais, não basta tomar decisões bem como ter posicionamentos como as demais, é preciso se destacar. Mais do que isso, é preciso planejar, pensar e agir diferente. E isso tudo em um tempo menor, uma vez que o mercado passa por constantes mudanças em um período de tempo cada vez mais reduzido. Para isso, as estratégias a serem adotadas e aplicadas devem ser utilizadas de forma coerente para os públicos. Ansoff e McDonnell (1993, p. 70) salientam que "basicamente, estratégia é um conjunto de regras de tomada de decisão para orientação do comportamento de uma organização".

De encontro a isso, as regras a serem utilizadas pelas marcas definirão os objetivos a serem cumpridos e seus resultados dependerão, além disso, da condução da marca para tais estratégias adotadas. Segundo Ansoff e McDonnell (1993) há quatro tipos distintos de regras no que tange às estratégias. A primeira diz respeito aos padrões que o desempenho do presente e futuro de uma organização é medida, em questão qualitativa esses padrões são os objetivos e em questão quantitativa são as metas. A segunda regra salienta as regras de desenvolvimento da relação com o ambiente externo, no sentido de quais produtos e tecnologias a empresa irá desenvolver, onde e para quem vender e como obterá vantagem diante da concorrência. $\mathrm{O}$ somatório destas regras é chamado de estratégia de produto e mercado, ou ainda, estratégia empresarial. A terceira regra estabelece as relações e processos internos da organização, o que é chamado de conceito organizacional. A quarta e última regra segmenta as regras pelas quais a empresa irá conduzir suas atividades diárias, chamadas, então, de políticas operacionais. 
Todavia, não apenas definir estratégias, mas é imprescindível utilizar estratégias correntes a marca ou organização, de acordo com sua realidade, sua área de atuação, seus públicos, e sua realidade. Hamel e Prahalad afirmam que (1995, p 325) "o problema não está na "estratégia", mas sim na noção específica de estratégia que predomina em muitas empresas", o que será definido a partir do planejamento pontual, de acordo com a realidade da empresa. O fundamental é planejar e por em prática estratégias cabíveis e coerentes para as empresas, não só por ter uma estratégia, mas por de fato ter uma estratégia condizente as características de uma empresa ou marca.

A estratégia pode ser percebida como uma aliada das empresas, uma vez que possui um poder de auxiliar em demandas. Quando planejada e bem executada, uma estratégia servirá tanto de estímulo para uma continuidade de planejamento e também como norteador caso a empresa enfrente necessidades ou crises. De acordo com Ansoff e McDonnell (1993, p.75) “A estratégia é uma ferramenta que oferece importante ajuda para lidar com a turbulência enfrentada pelas empresas". De encontro a isso, a estratégia deve ser projetada pela gestão das empresas, uma vez que conhecer seus públicos, seus serviços e produtos e todas as suas realidades é fundamental para um destaque entre as demais marcas. Corroborando a isso Ansoff e McDonnell (1993, p.75) afirma, ainda que a estratégia “portanto, merece atenção como uma ferramenta de gestão, não apenas para a empresa como também para uma ampla gama de organizações sociais".

Visto isso, pensar de modo diferente, gera valor para as marcas, uma vez que estando à frente das demais se destacam e atingem melhores resultados. Entretanto, para que as estratégias sejam de grande valia, é necessário o envolvimento de todos os públicos, não só o consumidor final, mas os funcionários e aqueles que fazem parte das ações estratégicas das marcas. Assim, se requer pensar novas formas sobre a organização e para isso é primordial "mobilizar os funcionários de todos os níveis em tomo de uma intenção estratégica, alavancar recursos para além das fronteiras da organização, encontrar e explorar oportunidades de espaços em branco" (HAMEL; PRAHALAD, 1995, p. 332). É preciso surpreender os clientes a todo momento e explorar novos espaços competitivos, para então criar vantagens competitivas e atrair novos consumidores.

Sob esta ótica, uma das formas de repensar as marcas e empresas e visar estratégias diferenciadas, as quais contribuem para a percepção da marca para seus públicos e também pode gerar uma possibilidade de aumento de consumidores diz respeito ao conceito da Lógica Dominante de Serviço (LDS). Este conceito de LDS visa novas percepções de marketing com 
o intuito de criação compartilhada de valor entre empresas e consumidores. Percebe-se que, a partir deste conceito, que não mais percebidas pelos produtos, as marcas podem ser percebidas pelos serviços, visto que geram experiências e proporcionam aos seus clientes a troca de benefícios e as vantagens e possibilidades que a marca gera para o consumidor.

Com isso, os consumidores passam a ter um olhar diferenciado para as marcas que lhe proporcionam benefícios, não apenas gerados pelo consumo do produto final, mas pelas vantagens que terão adquirindo um produto e em consequência a isso, os serviços. Assim, os públicos de forma geral passam a estreitar suas relações e valorizam as empresas e marcas que lhe ofereçam serviços mais vantajosos e melhores condições para uma aproximação e relação mais alinhada, não apenas obtida na compra, mas gerando um relacionamento com a empresa e marca (NICKELS; WOOD, 1999).

Em tempos atuais, a competitividade entre as marcas e empresas está cada vez maior, isto porque há mais opções de escolha para o consumidor, além disso, o acesso e geração de informações ocorre cada vez mais rapidamente, o que faz com que os consumidores não se tornem fiéis a apenas uma maraca, mas consumam de acordo com sua necessidade e percepções de vantagens para o consumo. Por isso, a necessidade de traçar caminhos diferenciados, que atendam às exigências de consumidores cada vez mais atentos ao que ocorre e que visam obter vantagens ao consumir. Além isso, um desafio constante para as marcas é satisfazer as necessidades dos clientes e, mais do que isso, superar as expectativas e surpreender aqueles que consomem os produtos e serviços de uma marca e a busca pelo êxito de uma organização (PRAHALAD; RAMASWAMY, 2004).

Nessa perspectiva, o foco da Lógica Dominante de Serviço (LDS) se dá na intangibilidade dos processos de troca, com o enfoque nas relações de interação entre empresa e consumidor, gerando criação de valor pelos serviços adquiridos e pelos valores percebidos a partir do consumo (VARGO; LUSH, 2004). Para isso, o consumidor adquire um papel fundamental para a Lógica Dominante de Serviço (LDS), uma vez que são os atores diretos para o sucesso da estratégia. É a partir dele que se avalia o sucesso das ações e se planeja os próximos paços, é a partir dele que se mede o resultado e se pondera os aspectos positivos e negativos das ações.

A aproximação das relações entre empresas e marcas e seus consumidores tem papel básico, uma vez que criar relações duradouras é o principal foco. Os consumidores que possuem as vantagens ao adquirir os produtos e serviços e passam ter longas relações disseminam isso para sua rede de contatos, gerando, assim, uma repercussão positiva da 
marca e atingindo cada vez mais novos públicos. Sendo assim, "a relação de troca do marketing se dá através de sucessivas interações e não de transações pontuais" (VARGO; LUSH 2004 apud BRASIL; SANTOS; DIETRICH, 2010, p. 4).

Assim, a lógica dominante de serviço tem a potencialidade para esclarecer o papel de troca entre os diferentes tipos de serviços. A LDS é utilizada como meio de enriquecer as percepções obtidas pelo marketing que até então uniam seus esforços para as propriedades intelectuais mais focadas na economia manufatureira de produção. É importante salientar que os consumidores não só compram ou necessitam se produtos, mais do que isso, necessitam dos serviços que as empresas oferecem, necessitam das experiências e relações com a marca e a avaliação destas ações que é o fator determinante das necessidades dos indivíduos (VARGO; LUSH, 2008). Corroborando a isso, Prahalad e Krishnan (2008, p. 21) afirmam que "o indivíduo situa-se no âmago da experiência. Se o lócus do valor se desloca de produtos e serviços para experiências, a criação de valor deve concentrar-se, quase por definição, em cada consumidor como indivíduo".

O que os consumidores buscam, então, diz respeito a um serviço único e singular, a partir de momentos diferenciados e que o façam ter uma relação muito próxima com a marca. Se sentir vinculado à ela e usufruir dos serviços em sua maior amplitude é o que o satisfaz com um consumo relacionado ao todo e não apenas com um produto adquirido em um único momento. Independente do bem produzido, o foco está no serviço prestado, tanto no número de serviços oferecidos quanto na sua qualidade, visando sempre aprender com os clientes e visando atingir suas necessidades particulares (VARGO; LUSH, 2004).

De encontro a isso, cabe salientar que o foco principal da mudança não se dá pelo destaque repentino do serviço, fugindo do foco oferecido pelos produtos da empresa até então, mas sim, nas combinações realizadas para a expansão da capacidade da difusão e troca de informações. Faz-se necessário alinhar os serviços prestados com os produtos oferecidos, fazendo uma relação direta e transformando estes serviços prestados de forma natural e relacional com os produtos. É a partir disso, que os serviços prestados a partir dos produtos consumidos trará um valor à marca e possibilitará nossas propostas da empresa, construindo uma relação mais intensa de forma natural e que trará vantagens tanto para a marca quanto para o consumidor. Grönroos $(2003$, p. 78$)$ salienta que “o valor [...] não está embutido nos recursos utilizados no processo de serviço, mas surge durante os processos de consumo ou utilização dos clientes, quando eles usam esses recursos em interações com fornecedor de serviço para alcançar um resultado para si próprio’. 


\section{HEINEKEN: UM CASO DE EXPERIÊNCIA DE MARCA E SEUS PÚBLICOS}

Uma senhora com muito estilo. Assim se pode definir a Cerveja Heineken. Formulada há cerca de 140 anos, a mesma é uma das mais consumidas do mundo, sendo adoradas pelos jovens e criando uma identidade muito forte com os seus públicos, tornando a mesma uma marca global e consolidada.

A história se inicia em 1864, na cidade de Amsterdã - Holanda, quando Gerard Adriaan Heineken comprou uma pequena cervejaria. O produto, inicialmente produzido para as massas, não agradava o dono da empresa, que tinha o desejo de transformar sua cerveja em um produto nobre, consumido pela alta sociedade da Holanda. A partir disso, Gerard percorreu a Europa atrás dos melhores ingredientes, e na Alemanha encontrou os melhores métodos de produção, ideais para criar a sua cerveja. Com a contratação de um alemão como responsável pela fermentação, o empresário voltou ao país de origem e aplicou os conhecimentos adquiridos. Após essa mudança no modo de produzir, a Heineken teve uma melhora expressiva na qualidade e começou a ganhar o mercado.

Em meados da década de 40, a Heineken expandiu-se para o restante da Europa, Estados Unidos e Ásia. Sua primeira ação de marketing, para que essa expansão começasse a tomar forma aconteceu durante os Jogos Olímpicos de 1928, em Amsterdã. Um avião desenhou nos céus da Holanda, com fumaça, o nome da marca. A partir desse momento, foi dada a largada para que a marca fosse reconhecida mundialmente. Nas décadas seguintes, a expansão cresceu em alta velocidade, e em 1990, a Heineken entrou no mercado brasileiro como produto de exportação, porém somente em 2010 adquiriu a divisão de cervejas do Grupo Femsa. Possui hoje sete fábricas em seis estados e emprega mais de 2.300 funcionários no país.

A empresa hoje produz sua principal cerveja, a Heineken (que possui o mesmo nome da empresa), chope, e mais 250 marcas diferentes, em todo o mundo, como por exemplo, Amstel, Tecate e as brasileiras Kaiser e Sol. A Heineken possui 165 cervejarias instaladas em 70 países e empregam mais de 85 mil pessoas em todo o mundo. De acordo com a consultoria Intrebrand, somente a marca Heineken, está avaliada em US\$ 3.939 bilhões, estando entre as 100 marcas mais valiosas do mundo. A empresa está em $3^{\circ}$ lugar no ranking de lucratividade entre as cervejarias, desde 2005 é uma das principais patrocinadoras da Copa dos Campeões da Europa e também patrocina grandes eventos de música como Rock In Rio e Lollapalooza. 
O processo de consolidação da marca Heineken se dá através de detalhes que diferenciam a mesma das demais, iniciando pela sua garrafa verde, um dos maiores símbolos da marca. A partir de 1930, a empresa trocou suas garrafas marrons pela cor verde, com um propósito comercial. Como a cervejaria começou a exportar seu produto, trocou a cor da garrafa para que o consumidor conseguisse diferenciar a marca das demais de forma visual, tornando a mesma mais atrativa aos olhos. Hoje, a garrafa verde ainda se diferencia das demais, tanto pela cor quanto pelo seu formato mais alongado e fino.

O rótulo também é cheio de significados e traz uma grande identificação visual para a marca. A estrela vermelha, presente na marca da cerveja e também na da empresa, remete aos cervejeiros medievais, que penduravam uma estrela nos barris para proteger a bebida, a partir dos elementos terra, fogo, ar, água e o quinto elemento, mágico, que garante a qualidade do líquido. As letras "e" também possuem um significado importante. Os mesmos são ligeiramente inclinados para cima, para remeter a ideia de um sorriso, dando uma aparência de sorriso à marca.

Mesmo sendo uma empresa consolidada e conhecida no mercado, a Heineken opta sempre pela inovação, a fim de conquistar novos públicos e fidelizar seus consumidores já existentes. Várias ações e estratégias são utilizadas, sendo o Heineken Bar uma delas. O mesmo surgiu através de uma pesquisa americana que apontou que a cerveja, depois do café, era o produto mais consumido em aeroportos em todo o mundo. A partir daí, a Heineken inaugurou, em 2007, a primeira unidade do Heineken Bar, no moderno aeroporto de Hong Kong. Existem outras duas unidades, em Nova York e em Amsterdã. O curioso é que a cerveja é a mais consumida dentro dos aviões das principais companhias aéreas mundiais.

Nessa perspectiva, o Bar Heineken se torna uma estratégia de Lógica Dominante de Serviço ao passo que utiliza o serviço como forma de disseminação da marca e até mesmo do próprio produto. $\mathrm{O}$ que se pode salientar é que os consumidores e públicos em geral não consomem ou necessitam de produtos, mas sim, precisam dos serviços prestados pelas marcas e partir da análise destes serviços é que se determinará se a marca atendeu a todas as necessidades. Assim, as marcas podem ganhar mantendo o consumidor como centro das transações, além de considera-lo um participante ativo no processo de troca (VARGO; LUSH, 2004).

Pode-se citar, também, outras estratégias de marketing da empresa, como a loja gelada e a Heineken Experience, sendo essa última, um projeto arrojado, levando o consumidor para a maior experiência de marca já vivida por eles. Em 2002, após várias reformas, o antigo 
prédio da cervejaria, que já havia tido parte de sua estrutura demolida, serviu de sede para a Heineken Experience. O museu oferece uma visita guiada e conta a história da empresa para o visitante, através de interações com o público. Durante os 90 minutos de passeio, o cliente entra no universo da marca, participando até do início do processo de fabricação da cerveja. Ao final do percurso, o mesmo pode degustar a cerveja recém produzida. O museu recebe cerca de 500 mil visitantes anualmente e virou ponto turístico e parada obrigatória na cidade de Amsterdã.

O museu é outro serviço utilizado pela marca para que atendam as necessidades dos consumidores, de forma emocional e experimental, com influência na imagem dos consumidores a partir de boas experiências com os serviços prestados. Nesta perspectiva, o cliente tem forte influência nos serviços prestados, uma vez que participa ativamente da transformação do serviço pelas marcas, por meio de trocas de conhecimentos e habilidades. Vargo e Lush (2004, p.7) afirmam que "O cliente é um cocriador do serviço. Marketing é um processo de fazer as coisas através da interação com o cliente. O cliente é essencialmente um recurso operante, funcionando apenas como um recurso operando".

Para elucidar os conteúdos abordados na presente pesquisa, demonstra-se, por meio da marca Heineken, uma ação de Experiência de Marca que engloba as definições de alguns autores aqui citados, bem como demonstra o envolvimento da marca com seus diferentes públicos e não apenas o consumidor final. A estratégia não se deu na venda direta na cerveja, visou trazer um tema que envolve todas as empresas, que é a contratação de um funcionário. Todavia, a marca buscou ser criativa e demonstrar outras formas possíveis de contratação, envolvendo ações diferenciadas, se preocupando com a opinião dos funcionários, divulgando o resultado em uma ação em um jogo de futebol, o que envolve outras marcas e, além disso, criando um vídeo com a situação, repercutindo de forma positiva as estratégias utilizadas pela marca e criando vínculos com os diversos públicos. Esta ação foi realizada em 2013.

Dessa forma, o vídeo foi organizado da seguinte forma: a primeira parte demonstra que atualmente a maioria dos candidatos vai preparado à uma entrevista de trabalho, sabendo tudo o que irá responder e sabendo aquilo que a marca busca. Falar algo que irá agradar quem está fazendo a entrevista é cada vez mais comum, inclusive, há muitos vídeos com orientações de como se portar e o que responder em uma entrevista. Por isso, a proposta desta entrevista é criar situações em que o entrevistado não está preparado, para avaliar, então, como ele reage e quais as respostas espontâneas do entrevistado. Assim, a primeira pergunta que foi feita para 
os entrevistados foi: Qual seu estilo de gestão? A maioria das respostas se deu da mesma forma: Apaixonado, conforme pode-se visualizar na Figura 1.

Figura 1- Estilo de Gestão

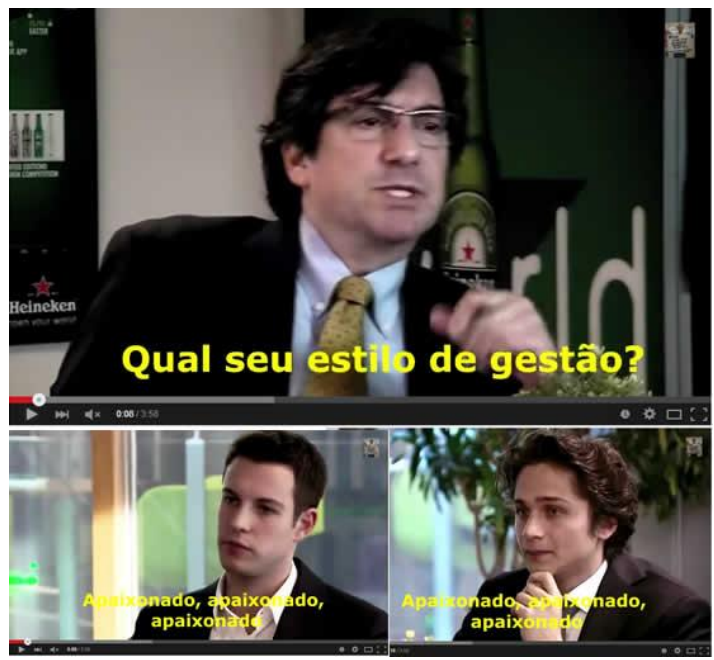

Fonte: Adaptado pela autora de Youtube (2014)

Quando perguntados qual a maior fraqueza, grande parte respondeu: teimoso. Isso demonstra que as pessoas respondem aquilo que sabem que gostariam que fosse e falasse, sem autenticidade ou demonstrar de fato suas características, conforme pode ser visto na Figura 2.

Figura 2- Maior Fraqueza

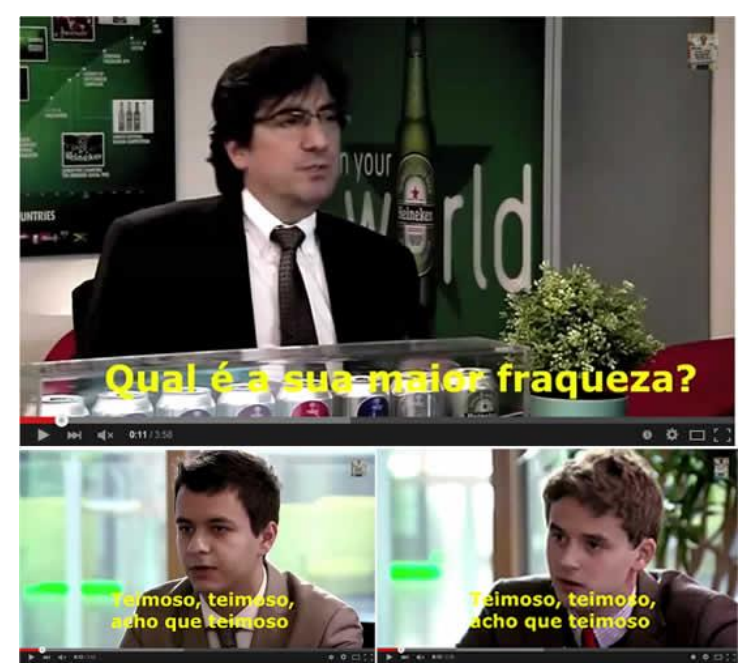

Fonte: Adaptado pela autora de Youtube (2014)

Surge então uma missão a ser atendida pela marca: Como encontrar o estagiário ideal para o setor de eventos e patrocínios dentre 1734 candidatos? Nasce, então, a proposta de Experiência de Marca: The Candidate, julgada como a entrevista que você não pode se preparar. A entrevista foi separada por diferentes testes, sendo o teste 1 nomeado como A Largada, de acordo com a Figura 3. A recepcionista do candidato leva-o até a sala do chefe, 
porém, de mãos dadas e o chefe o recebia e o acompanhava a até a mesa também de mãos dadas. Por mais estranho que os candidatos achassem, mantinham as mãos dadas, como forma de atender os requisitos da entrevista. Quando questionados se sentiram à vontade ficavam sem resposta e alguns até mesmo responderam que sim.

Figura 3- A

\section{Largada}

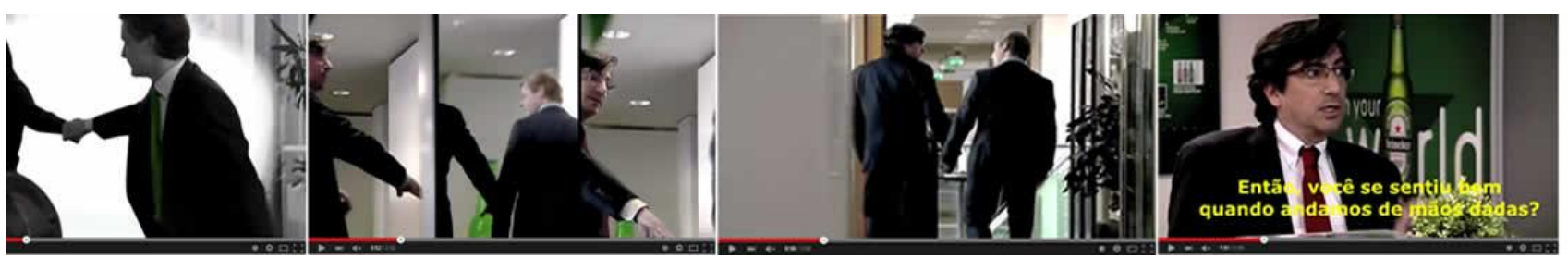

Fonte: Adaptado pela autora de Youtube (2014)

O teste 2 foi identificado como Primeiros Socorros, no qual o chefe simulava passar mal e analisaram as reações dos entrevistados. Alguns tentavam ajudar, outros ficaram sem reação e alguns procuraram ajuda, mas de fato não sabendo como reagir no sentido que não estavam preparados para aquele momento, de acordo com a Figura 4.

Figura 4- Primeiros Socorros

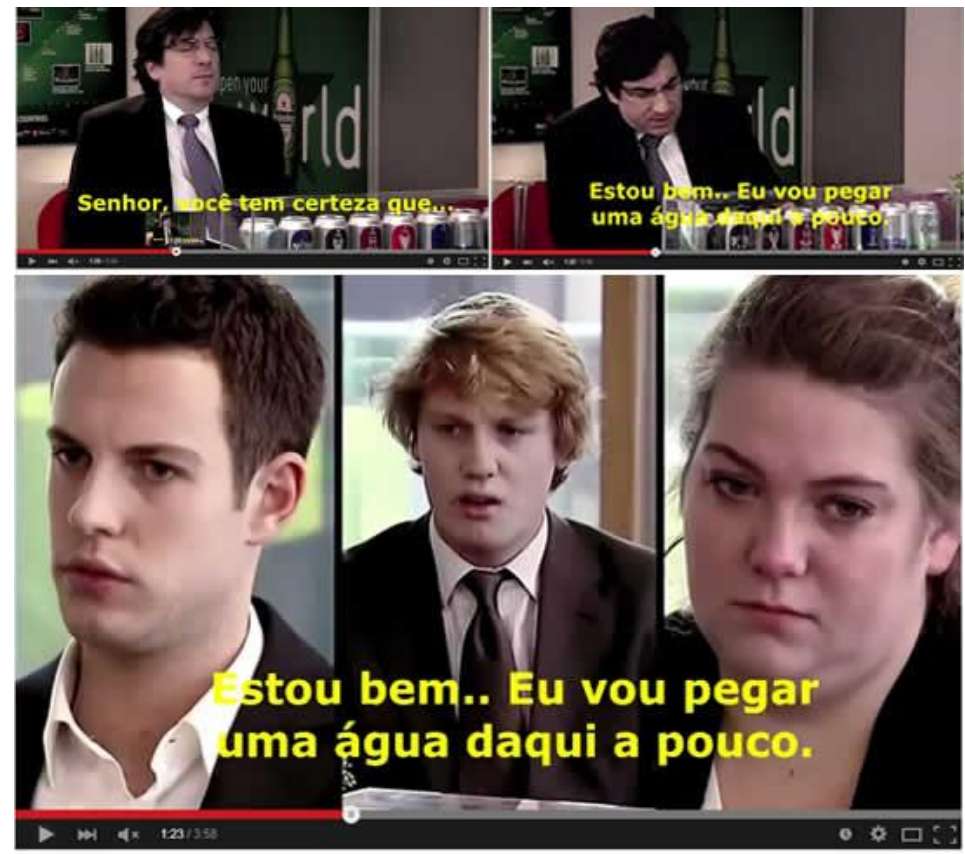

Fonte: Adaptado pela autora de Youtube (2014)

O teste 3, então, é Saída, no qual o chefe fez a seguinte pergunta: Intenso e apaixonado ou frio e calculista? Ao responderem frio e calculista o chefe dizia que a resposta estava 
errada, mas um dos entrevistados respondeu: intenso e apaixonado, as outras pessoas são contagiadas pelo meu entusiasmo. Eis que durante a entrevista uma funcionária chama o entrevistado e seu chefe para se retirarem pois estava ocorrendo um incêndio. Ao saírem do local de trabalho, os candidatos se deparavam com uma situação: os bombeiros estavam preparando para que um funcionário se atirasse do prédio e eles iriam segurá-lo, porém, ainda havia um lugar disponível e chamavam os funcionários. Todos estavam com medo e não queriam participar de tamanha responsabilidade, até que um dos candidatos se oferece e ajuda a motivar o funcionário a se atirar, estando totalmente engajado na situação, elucidado na Figura 5.

\section{Figura 5- Saída}

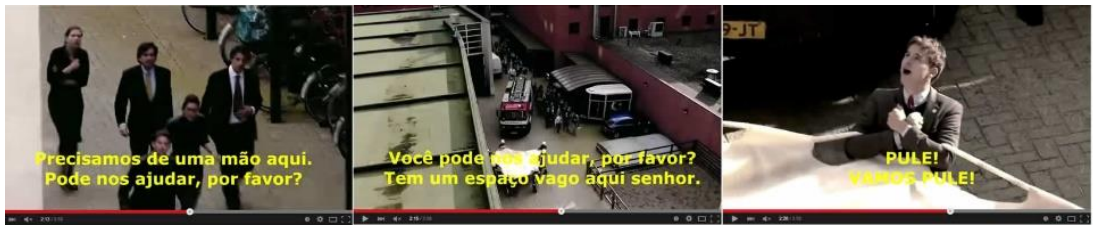

Fonte: Adaptado pela autora de Youtube (2014)

Após isso, os três melhores candidatos passaram por uma votação, a qual houve o envolvimento dos funcionários, que escolheram o melhor candidato para esta vaga em um site interno, que pode ser visualizado na Figura 6. Cabe salientar que inúmeros outros públicos podem ser atingidos com as estratégias, como o público interno (funcionários), a comunidade, os formadores de opinião, e cada um possui a sua importância e relevância para a marca como um todo. Sobre os públicos de interesse pode-se identificar "pessoas ou outras empresas que têm algum interesse no resultado da organização, como investidores ou acionistas, fornecedores, revendedores, funcionários, mídia, sociedade em geral, incluindo, entre outros grupos de clientes e de consumidores" (DUAILIBI, 2009, p.59).

\section{Figura 6- Votação dos Funcionários}

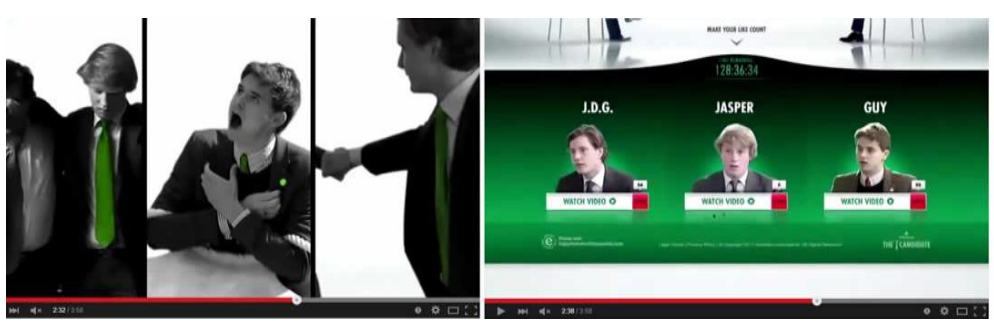

Fonte: Adaptado pela autora de Youtube (2014)

O mais votado foi convidado para um jogo de futebol do time Juventus, o qual demonstrou o mesmo entusiasmo para a abertura do jogo. Sendo assim, o candidato Guy 
Luchting foi escolhido e a divulgação foi feita no telão do estádio de futebol, em frente a todos os torcedores presentes no jogo, demonstrado abaixo na Figura 7.

Figura 7- O Resultado

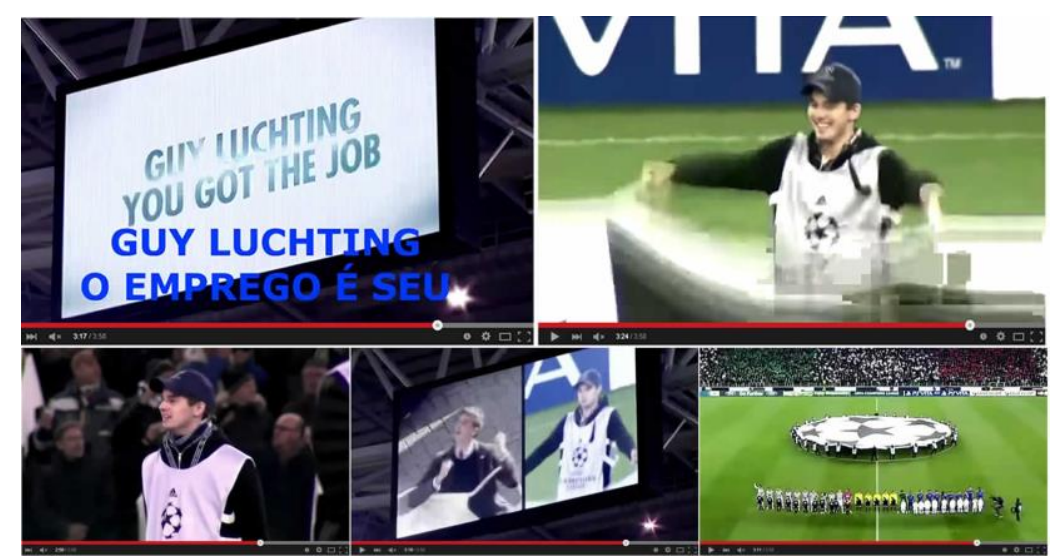

Fonte: Adaptado pela autora de Youtube (2014)

A partir desta ação de Experiência de Marca, percebe-se que a Heineken buscou trazer à tona um tema bastante presente nas empresas, todavia, de forma diferenciada e de forma a atrair e envolver seus públicos. Muitos fãs e consumidores tem interesse em trabalhar em uma marca como a Heineken, por isso, a preocupação de estarem informados e buscarem respostas preparadas em uma entrevista. Porém, mais do que isso, a marca quer contratar pessoas que se diferenciam pela autenticidade e criatividade, capazes de passar por situações diversas e conseguirem ter bons resultados. Além disso, há a preocupação da marca em envolver seus funcionários e ouvi-los, se importando com o que pensam, acreditam e os envolvendo em suas decisões.

Cada sujeito tem pensamentos e interpretações muito pessoais, de acordo que o que pode ser positivo e envolvente para um, por não ser para outro. O que toca e gera sentimento para cara indivíduo é relativo, assim como, o que estimula, o que faz gerar o entusiasmo, o que o faz consumir. "o entusiasmo, no entanto, é maior, e é esse o sentimento que deixamos falar mais alto. As coisas mais simples são as que tocam mais fundo o coração" (FERRÃO, 1997, p. 124).

Visto isso, a estratégia utilizada para a divulgação do resultado da contratação envolveu não apenas os consumidores da marca, mas outros públicos que estavam no local em função de um esporte, mas que foram envolvidos e surpreendidos pela marca, criando uma relação de vínculo emocional e fixando a ação e a marca em suas escolhas. De fato, a marca conseguiu atingir diversos públicos, uma vez que não fixou na venda, mas sim nos serviços 
prestados e no que a marca pode proporcionar e, principalmente, criou fortes relações com diversas pessoas em uma única ação realizada.

A LDS visa a percepção da geração de serviços vantajosos entre empresa e consumidor, mas não visa apenas a venda final, foca nas relações criadas e na geração de sentido produzido a partir da percepção dos serviços. Isso se aproxima do marketing de relacionamento, uma vez que zela pela boa relação e por relacionamentos mais estreitos, que pode ser exemplificado como "processo de estabelecer e manter relacionamentos de longo prazo mutuamente benéficos entre organizações e seus clientes, empregados e outros grupos de interesse" (NICKELS; WOOD, 1999, p. 5).

O exemplo utilizado nesta pesquisa demonstra a capacidade da marca em criar ações, criar vínculos emocionais, oferecer mais do que produtos, serviços que criam vantagens competitivas não apenas para os consumidores, mas para os públicos de forma geral e também para a própria marca.

\section{CONSIDERAÇÕES FINAIS}

Não há óbices para frisar que de forma ampla a economia criativa não é algo certo, definido e regrado. Para se ter sucesso na economia criativa é preciso arriscar, acreditar em algo único e singular, o destaque se dá pelo novo, não pelo comum. Dessa forma, não se pode afirmar a assertividade de uma ação gerada, sendo ela em forma de produto, serviço ou conteúdo. Nessa perspectiva, se reafirma a relevância da pesquisa e planejamento, a fim de avaliar de forma assertiva as criações. Não há fórmulas exatas ou tecnologias previsíveis, apenas a eficiência e eficácia na utilização de novas tecnologias, novos conceitos em pró a geração da criatividade.

Essas concepções se valem, também, quando se trata de Experiência de Marca e a Lógica Dominante de Serviço, visto que seus conceitos passam por transformações e estão em desenvolvimento. Frente ao exposto, cabe salientar que as Experiências de Marca geram manifestações de diferentes ambitos possuem grande relevância e resultados positivos se bem aplicadas. Isso porque se planejadas, ocorrer em um lugar propício para ações, envolver os públicos e criar vínculos com estes, o retorno positivo agregará valor às marcas. Nessa perspectiva, a possibilidade de participar das Experiências de Marca auxilia nessa concepção dos públicos, criando vínculos maiores e fazendo com que estes sejam estimulados de forma emocional. 
A partir disso, percebe-se que as experiências podem ser estratégias relevantes para as marcas, uma vez que proporcionam momentos singulares, ocasiões únicas para os públicos, envolvendo o emocional dos consumidores com as possibilidades de experiência.

A partir dos conceitos identificados nesta pesquisa, pode-se identificar que a escolha e definição das estratégias são decisórias para o sucesso das marcas, uma vez que o bom resultado das ações será o reflexo de estratégias utilizadas de forma coerente e em destaque às demais marcas. Por isso a Lógica Dominante de Serviço vem como um somatório para resultados relevantes, uma vez que a prática de não apenas vender produtos em vendas soladas, mas sim, criar relacionamentos duradouros e vínculos entre marca e consumidor, torna a marca mais valiosa e gera vantagens competitivas para as marcas e seus públicos. Se utilizar de serviços de qualidade e que demonstram aquilo que a marca é fazem com que as marcas destaquem-se entre outras, de forma criativa e vantajosa.

Sob esta ótica, pode-se afirmar que a marca Heineken está em destaque a estas questões, gerando uma preocupação e bons resultados no que tange às estratégias utilizadas e os resultados obtidos em suas Experiências de Marca. Não só a venda isolada de cerveja, a Heineken gera experiência, cria vínculos com seus diferentes públicos e vende serviços que resultam em relacionamentos intensos a partir dos vínculos emocionais. A marca demonstra uma forma de envolver diferentes públicos, como os vistos neste etudo, a partir de um caso de contratação de funcionário, o qual envolveu não apenas a gestão da marca, mas os consumidores, funcionários, mídia, fãs da marca e até mesmo públicos que necessariamente não consomem o produto, mas possuem uma relação de afeto com a marca.

Como estudos futuros sugere-se o comparativo das estratégias utilizadas para as experiências utilizadas por diferentes marcas, a fim de comparar e compreender de que forma as marcas se posicionam e se relacionam, a partir das experiências, com seus públicos. Além disso, sugere-se a realização de análise de outras marcas, compreendendo as formas e preocupações sob distintas visões. Corroborando a isso, sugere-se que mais pesquisas quanto a Experiência de Marca, qualificando pesquisas e justificando as ações que vem sendo cada vez mais atuais e presentes no mundo contemporâneo.

\section{REFERÊNCIAS}

ANSOFF, H. Igor; MCDONNELL, Edward J. Implantando a Administração Estratégica. São Paulo, SP: Atlas, 1993.

ARGENTI, Paul A. Comunicação Empresarial. Rio de janeiro, RJ: Elsevier, 2006. 
BRAINSTORM9. Disponível em < http://www.brainstorm9.com.br/17413/opiniao/eventosbrand-experience-e-apropriacao-de-memorias >. Acesso em março de 2014.

Disponível em <http://www.brainstorm9.com.br/46837/diversos/pley-umnetflix-dos-legos-aluga-pecinhas-em-planos-mensais/> Acesso em março de 2014.

CAVALCANTI, Marcos. Gestão de Empresas na sociedade do conhecimento: um roteiro para a ação. Rio de Janeiro, RJ: Campus, 2001.

DUALIBI, Roberto. Criatividade \& Marketing. São Paulo, SP: M. Books, 2009.

DUARTE, J. Entrevista em Profundidade. In: DUARTE, J. BARROS, A. Métodos e técnicas de pesquisa em comunicação. São Paulo: Atlas, 2006, p. 62 a 82

DUARTE, M. Estudo de caso. In: DUARTE, J. BARROS, A. Métodos e técnicas de pesquisa em comunicação. São Paulo: Atlas, 2006, p. 215 a 235

FASCIONI, Lígia. Quem a sua empresa pensa que é? Rio de Janeiro, RJ: Editora Ciência Moderna, 2006

FERRÃO, Carmen. Em busca da Emoção: o sentimento transforma o marketing nesta passagem de século. Porto Alegre: Sulina, 1997.

FLORIDA, Richard L. A ascensão da classe criativa. Porto Alegre, RS: L\&PM, 2011.

GOOGLE. Disponível em <www.google.com.br>. Acesso em maio de 2014.

GRACIOSO, Francisco (Org). As novas arenas da comunicação com o mercado. São Paulo, SP: Atlas, 2008.

GRÖNROOS, Christian. Marketing: gerenciamento e serviços : a competição por serviços na hora da verdade .2. ed. Rio de Janeiro, RJ: Elsevier, 2003.

HAMEL, Gary; PRAHALAD, C. K. Competindo pelo Futuro: estratégicas inovadoras para obter o controle do seu setor e criar os mercados de amanhã. Rio de Janeiro, RJ: Campus, 1995.

HANSON, Dennis. Indústrias Criativas. Rio de Janeiro: Revista Eletrônica Sistemas e Gestão, 2012.

HEINEKEN BRASIL. Disponível em <http://www.heinekenbrasil.com.br/idade.aspx>. Acesso em dezembro de 2014.

HEINEKEN THE CANDIDATE. Disponível em < https://www.youtube.com/watch?v=zKeFBsU5Z5k>. Acesso em dezembro de 2014.

HILL, Sam. 60 Tendências em 60 minutos. São Paulo, SP: Futura, 2003. 407 p. 
HOWKINS, John. Economia Criativa - Como ganhar dinheiro com ideias criativas. São Paulo, SP: M. Books do Brasil, 2013.

JENKINS, Henry. Cultura da convergência. São Paulo, SP: Aleph Editora, 2008.

JUCÁ, Fernando e TORTORELLI, Francisco. O jogo das marcas: inspiração \& ação. São Paulo, SP: Cultrix, 2008.

KREUTZ, Elizete de Azevedo. A Construção de Marcas Mutantes. In Chasqui. Quito: Equador, 2012, No. 119.

LANDRY, Charles. Origens e futuros da cidade criativa. São Paulo, SP: SESI-SP editora, 2013.

LEVINSON, Jay Conrad. Criatividade de Guerrilha - torne o marketing de sua empresa irresistível com o poder dos memes. Rio de Janeiro: MAUAD, 2004.

MARTINS, José Roberto. Branding: um manual para você criar, gerencias e avaliar marcas. 2006. 348 p.

MUNDO DAS MARCAS. Disponível em http://mundodasmarcas.blogspot.com.br/2006/05/heineken-terra-verde.html. Acesso em dezembro de 2014.

NICKELS, William G.; WOOD, Marian Burk. Marketing: relacionamentos, qualidade, valor. Rio de Janeiro: LTC, c1999.

NIEMEYER,_Carla. Marketing no design gráfico. 3. ed. Rio de Janeiro, RJ: 2AB, 2002. $64 \mathrm{p}$.

PENN, Gemma. Análise Semiótica de imagens paradas. In BAUER, Martin e GASKELL, George. Pesquisa Qualitativa com texto, imagem e som: um manual prático. Petrópolis: Vozes, 2002, p. 319-342.

PRAHALAD, C. K.; KRISHNAN, M. S. A nova era da inovação. Rio de Janeiro, RJ: Campus, 2008.

PRAHALAD, C. K.; RAMASWAMY, Venkatram. O Futuro da competição: como desenvolver diferenciais inovadores em parceria com os clientes. Rio de Janeiro, RJ: Campus, 2004.

PRODANOV, Cleber Cristiano; FREITAS, Ernani Cesar. Metodologia do Trabalho Científico: métodos e técnicas da pesquisa e do trabalho acadêmico. Novo Hamburgo, RS: Feevale, 2009. 288 p.

REIS, Ana Carla Fonseca. Cidades Criativas: da teoria à prática. São Paulo, SP: SESI-SP editora, 2012.

RIES, Al. As 22 consagradas leis de marca. São Paulo: Makron Books, 2000. 
SCHMITT, Bernd. Marketing experimental. 1 ed. São Paulo, SP: Nobel, 2001. 272 p

SEMPRINI, Andrea. A marca pós-moderna: poder e fragilidade da marca na sociedade contemporânea. São Paulo, SP: Estação das Letras Editora, 2006.

STUMPF, I. Pesquisa bibliográfica. In: DUARTE, J. BARROS, A. Métodos e técnicas de pesquisa em comunicação. São Paulo: Atlas, 2006, p.51 a 61.

TMINCENTIVOS. Disponível em <http://www.tmincentivos.com.br/site/brand>. Acesso em março de 2014.

VARGO, Stephen L; LUSCH, Robert f. A New Dominant Logic. Evolving to a New Dominant Logic, Journal of Marketing, v.68, p. 1-17, jan. 2004.

. Service-dominant logic: continuing the evolution, Academy of Marketing Science, p. 1-10, 2008.

YAMAOKA, E. J. O Uso da Internet. In: DUARTE, J. BARROS, A. Métodos e técnicas de pesquisa em comunicação. São Paulo: Atlas, 2006, p. 146 a 162

\section{Original recebido em: 06/04/2015}

Aceito para publicação em: 18/02/2016

Bruna Schuck Nunes

Mestranda em Indústria Criativa na Universidade Feevale, Novo Hamburgo, RS. Especialista em Comunicação Estratégica e Branding da Universidade Feevale, Novo Hamburgo, RS.

Graduada em Relações Públicas pela Universidade Feevale.

Mary Sandra Guerra Ashton

Doutora em Comunicação Social. Pesquisadora e Docente no Mestrado em Indústria Criativa na Universidade Feevale, Novo Hamburgo, RS.

Dusan Schreiber Doutor em Administração. Pesquisador e Docente no Mestrado em Indústria Criativa na Universidade Feevale, Novo Hamburgo, RS.

Serje Schmidt

Doutor em Administração. Pesquisador e Docente no Mestrado em Indústria Criativa na Universidade Feevale, Novo Hamburgo, RS.

Esta obra está licenciada sob uma Licença Creative Commons. 